\title{
OLHARES SOBRE A VIOLÊNCIA NO NAMORO: UM PROJETO COM ADOLESCENTES DO ENSINO SECUNDÁRIO
}

\author{
Joana AFONSO ${ }^{1}$ \\ Filomena TEIXEIRA ${ }^{2}$
}

RESUMO: A violência nas relações de namoro tem vindo a aumentar nos últimos anos, tornando-se relevante a implementação, em contexto escolar, de projetos de intervenção visando a sua prevenção. O principal objetivo do projeto foi diminuir a legitimação de atitudes de violência nas relações de namoro. $\mathrm{O}$ recurso à exploração de videoclipes constituiu uma estratégia inovadora nas práticas de prevenção da violência no namoro, permitindo aos e às adolescentes desenvolverem um olhar crítico sobre a informação por eles veiculada. O projeto foi implementado numa escola do distrito de Leiria. Destinou-se a alunos/as do ensino secundário envolvendo pais, mães e encarregados/as de educação. Foram feitas três sessões numa turma de 15 alunos/as do $12^{\circ}$ ano que, posteriormente, dinamizaram uma sessão de sensibilização em cada uma das restantes turmas do ensino secundário e outra dirigida a pais, mães e encarregados/as de educação. Para avaliar o impacte das sessões realizadas recorreu-se à análise de fichas de exploração do videoclipe e respetiva letra e à versão portuguesa da Escala de Atitudes Face à Violência no Namoro (EAVN). Registou-se uma diminuição estatisticamente significativa das atitudes legitimadoras de violência nos/as alunos/as sujeitos à intervenção e a maior parte dos e das participantes referiu a relevância deste tipo de ações tendo gostado das atividades e estratégias utilizadas. As atividades dinamizadas, em particular a utilização de videoclipes e a preparação, pelos/as alunos/as, de sessões de sensibilização constituem um contributo a valorizar nas ações de prevenção da violência no namoro.

PALAVRAS-CHAVE: Violência no namoro. Videoclipes. Sexualidade e media. Intervenção na escola.

\section{Enquadramento teórico}

A violência doméstica é considerada uma violação dos direitos humanos e cada vez mais um problema de saúde pública (KRUG et al., 2002).

\section{$\underline{\text { Sexualidade e educação }}$}

\footnotetext{
${ }^{1}$ Mestre em Educação para a Saúde. Professora do Ensino Secundário do Agrupamento de Escolas de Porto. Mira de Aire - Portugal. 2485-050 - joanamra1 @ gmail.com.

${ }^{2}$ Investigadora no Centro de Investigação Didática e Tecnologia na Formação de Formadores (CIDTFF). UA - Universidade de Aveiro. Aveiro - Portugal. Professora Coordenadora. ESEC - Escola Superior de Educação de Coimbra. Coimbra - Portugal. 3030-329 - filomena.tx@gmail.com.
} 
Hoje em dia, apenas uma quantidade muito pequena de jovens recebe formação em educação em sexualidade, o que os/as deixa vulneráveis a coação, abuso, exploração, gravidez não oportuna e infeções sexualmente transmissíveis, como o VIH/Sida (UNESCO, 2010). As consequências da desinformação numa sociedade que se diz da informação fazem surgir a necessidade de uma educação em sexualidade adequada à idade e culturalmente relevante, com informações cientificamente corretas, realistas, e sem pré-julgamento. Ao transitar para a idade adulta os e as adolescentes devem estar informados/as e equipados/as com os conhecimentos e competências apropriados para fazer escolhas responsáveis na sua vida social e sexual (UNESCO, 2010).

Em Portugal a Educação Sexual está prevista na Lei $n^{\circ}$ 60/2009, regulamentada


maus tratos e das aproximações abusivas" constitui uma das temáticas da referida portaria. Apesar disso, há pais e mães que demonstram alguma relutância e preocupação acerca dos efeitos da educação em sexualidade, baseadas em informações limitadas ou em falsos conceitos sobre a natureza e efeitos dessa educação. Uma vez que as percepções e comportamentos dos e das jovens são influenciados por valores familiares e comunitários, normas e condições sociais, importa procurar a cooperação e apoio das famílias e da comunidade (UNESCO, 2010).

\section{Violência no namoro}

O combate à violência doméstica, que engloba a violência no namoro, tem vindo a assumir-se como um dos objetivos nucleares para que se alcance uma sociedade mais justa e igualitária. O IV Plano Nacional contra a Violência Doméstica (2011-2013) (PORTUGAL, 2010), doravante PNCVD, considera-a uma grave violação dos direitos humanos. O estudo nacional Health Behaviour in School-aged Children - HBSC de 2010 (MATOS, M. G. et al., 2010) revela que 13,5\% dos e das jovens tiveram a primeira relação sexual porque não queriam que o/a parceiro/a ficasse zangado/a.

A violência numa relação de intimidade é qualquer comportamento dentro de uma relação íntima que possa causar danos físicos, psicológicos ou sexuais ao parceiro ou à parceira. Inclui atos de agressão física (esbofetear, golpear, pontapear ou bater), abuso psicológico (intimidação, constante rebaixamento ou humilhação), relações sexuais forçadas ou qualquer outro comportamento de controlo (isolar a pessoa da 
família e amigos/as, monitorizar os seus movimentos e limitar o acesso a informação ou assistência) (KRUG et al., 2002). Estes comportamentos são, frequentemente, ignorados ou considerados menos significativos, simplesmente porque as duas pessoas estão envolvidas numa relação de grande proximidade (WEKERLE; WOLFE, 1999). Entre as principais consequências para a vítima da violência nas relações de intimidade, estão a desordem de stress pós-traumático, a baixa autoestima, a depressão, as reações psicossomáticas e o decréscimo do rendimento profissional, uma auto percepção desvalorizada, um ceticismo e um sentimento de impotência que as impede de se perceberem como seres com poder e direitos (MATOS, 2002 apud CARIDADE; MACHADO, 2006), podendo mesmo em alguns casos resultar em homicídio ou suicídio feminino (WHO, 2006; ACKARD et al., 2007). Poderá ainda haver uma relação entre a violência no namoro e comportamentos sexuais de risco que frequentemente levam a gravidezes não oportunas e infeções sexualmente transmissíveis (SILVERMAN et al., 2001; WHO, 2006).

A forma mais óbvia de violência no namoro envolve a força física seja por ameaça ou agressão. Apesar de ser este o tipo de comportamento mais estudado e avaliado, faz com que se desprezem outros tipos de comportamentos coercivos ou agressivos, muitas vezes exibidos nas relações de namoro, e que podem ter consequências igualmente graves (CORNELIUS; RESSEGUIE, 2007). Muitas vítimas experienciam mais de um tipo de violência, admitindo que o/a agressor/a fez ameaças ou tentou fazer-lhes mal e os/as forçou a terem contatos sexuais (AMAR; GENNARO, 2005). Quando a relação se prolonga no tempo, é habitual a violência aumentar em termos de frequência e gravidade (MAGALHÃES, 2010). Efetivamente, de uma forma geral, os casamentos abusivos são precedidos de relações de namoro violentas e caracterizadas por estratégias de controlo e restrição da autonomia da mulher (MATOS, 2000 apud CARIDADE; MACHADO, 2006).

Apesar de, nas pessoas adultas, as vítimas de violência numa relação de intimidade serem mais frequentemente as mulheres (SAN MIGUEL; FERNÁNDEZ, 2010; KRUG et al., 2002; MATOS, 2006), entre adolescentes as situações de violência e abuso poderão ser menos diferenciadas entre os sexos (ORTEGA; RIVERA; SÁNCHEZ, 2008; O'LEARY et al., 2008) e ocorrem frequentemente no contexto de relações de namoro.

Inicialmente muitos/as adolescentes não interpretam os comportamentos violentos como sendo de abuso, uma vez que não estão ainda familiarizados com as 
expectativas e limites de uma relação de intimidade (WEKERLE; WOLFE, 1999). Associada a esta inexperiência, está ainda a necessidade de emancipação e de independência dos e das jovens nesta fase (MATOS et al., 2006). Não sabendo como se comportar numa relação de namoro, ficam vulneráveis a mensagens imprecisas quer por parte da família, dos/as amigos/as (JOHNSON et al., 2005) e dos media (CONNOLLY et al., 2010 apud HAYS et al., 2010). Estes fatores podem fazer crescer a crença romantizada de que o ciúme e o controlo são sinais de amor, levando a que muitos/as jovens não reconheçam a violência que praticam ou a que são sujeitos/as. Também o uso generalizado das novas tecnologias pode alterar os mecanismos da violência no namoro. Os membros de um casal estão constantemente disponíveis, um para o outro, através de telemóvel ou outro meio de comunicação. O correio eletrônico e mensagens de texto estão facilmente acessíveis para escrutínio por um/a parceiro/a inseguro/a e, mesmo após o fỉm de uma relação, continuam contactáveis pelo/a parceiro/a, nomeadamente através do telemóvel e das redes sociais (DRAUCKER; MARTSOLF, 2010). Quando reconhecem a situação de violência, são estes meios de comunicação que implicitamente forçam a sua manutenção, para evitar a divulgação de dados que possam prejudicar a reputação dos e das adolescentes e o julgamento dos pares. Quando decidem denunciar situações de abuso, poucos/as são os/as que se dirigem a uma pessoa adulta como pais, mães ou professores/as (HENTON et al., 1983; MATOS, M. G. et al., 2010). A maioria recorre a amigos/as (HENTON et al., 1983) que, apesar de lhes darem apoio, não se revelam eficazes quanto ao abandono da relação violenta (JACKSON; CRAM; SEYMOUR, 2000).

Apenas 1/3 dos e das adolescentes admite que terminaria a relação a seguir a um ato violento (BETHKE; DEJOY, 1993), sugerindo que, para muitos/as, um relacionamento violento não é razão para terminar um namoro (GRAY; FOSHEE, 1997). Apesar de verem negativamente os/as agressores/as, alguns/mas adolescentes encaram os seus comportamentos violentos como aceitáveis e apresentam como razões para justificar os seus comportamentos de abuso, a legítima defesa, o ciúme, o aliviar das frustrações e necessidade de poder, o uso de substâncias, relacionamentos anteriores com violência, problemas de comunicação e necessidade de filiação (HAYS et al., 2010; MANGANELLO, 2008; CARIDADE; MACHADO, 2006). Um estudo de Machado, Matos e Moreira (2003 apud MATOS, M. et al., 2006) em estudantes universitários/as concluiu que, na generalidade, apresentam um baixo nível de concordância com as crenças legitimadoras da violência sendo os estudantes do sexo 
masculino os que revelaram perceções mais tolerantes acerca da violência. A falta de consciência acerca dos comportamentos apropriados numa relação de namoro poderá indiciar que o número de casos de violência no namoro pode estar subestimado (LEWIS; FREMOUW, 2001).

Para evitar o desenrolar de acontecimentos traumáticos e difíceis de ultrapassar, é crucial dar-se particular atenção à prevenção da violência no namoro (PORTUGAL, 2010). Os programas são mais bem-sucedidos quando ainda não existam situações de violência no namoro (FOSHEE et al., 1996). Por isso, muitos profissionais sugerem intervenções, desde cedo, nas escolas enquanto a constituição de relações de namoro ainda está numa fase embrionária (SUDERMANN; JAFFE; HASTINGS, 1995). Estes programas deverão incluir formação sobre diversas formas de violência nas relações, sinais de alerta, as estratégias de intimidação, poder e controlo e ainda o desenvolvimento de capacidades de comunicação e resolução de conflitos com o objetivo estabelecer relações saudáveis (O’KEEFE, 2005). A intervenção deverá ainda ser destinada a ambos os sexos uma vez que, relativamente à violência no namoro, não parece existir uma elevada diferenciação por género (O'LEARY et al., 2008). A diversificação de atividades usadas nas intervenções poderá constituir uma estratégia relevante para provocar mudanças ao nível dos comportamentos (MATOS, M. et al., 2006). Importa ainda dirigir os esforços não apenas para a prevenção de comportamentos de risco, mas também para a promoção de comportamentos saudáveis. É importante deixar os adolescentes fazerem o seu percurso, mas garantindo que estes tomam decisões seguras e responsáveis (SAAVEDRA, 2010).

\section{Sexualidade, media e violência no namoro}

Os media constituem uma das fontes a que os e as adolescentes recorrem em busca de informação sobre como viver a sua sexualidade. A importância dos media é inquestionável, seja ela na forma impressa, televisiva, radiofónica ou eletrônica. Dados do HBSC, para adolescentes portugueses, referem que mais de metade vê entre uma a três horas de televisão por dia e mais de quatro horas por dia ao fim-de-semana. Ward (2003) referencia um estudo de 1997 realizado pela Kaiser Family Foundation \& Children Now onde os e as adolescentes apontaram os media como a sua fonte principal de informação acerca da sexualidade e saúde sexual. Alguns admitiram procurar nos 
filmes e TV exemplos de atos românticos. O autor refere ainda que tem sido subestimada a influência dos media nas concepções relacionadas com sexualidade.

A música tem grande impacto na socialização de adolescentes. Existe cada vez mais oferta no mundo da música, sendo que muitas das letras são explícitas nas suas referências as drogas, suicídio, morte, violência, sexo, entre outros. Os e as jovens ignoram os conteúdos sexuais das letras, interpretando as suas canções favoritas centrando-se em temas relacionados com amor, amizade, crescimento, diversão, entre outros. Os gostos musicais dos e das adolescentes constituem uma forma de integração num grupo de pares (COUNCIL ON COMMUNICATIONS AND MEDIA, 2009). Os e as adolescentes idolatram as estrelas da música tentando construir uma imagem de si próprios à semelhança do seu ídolo (RICH et al., 1998). Uma análise ao canal MTV Rock's, em música de todos os géneros, demonstrou que em mais de $80 \%$ dos videoclipes com violência, os heróis eram os/as agressores/as (STRASBURGER; DONNERSTEIN, 1999). Cenas de agressão protagonizadas pelos seus heróis e heroínas servem para normalizar, tornar aceitável e romantizar o uso da violência interpessoal para resolver conflitos, libertar a fúria e conquistar objetivos pessoais (RICH et al., 1998).

Apesar dos ganhos das mulheres na luta pela igualdade de direitos, nos videoclipes os estereótipos de género continuam evidentes sendo as personagens femininas mais afetuosas, dependentes, subservientes e carinhosas e os personagens masculinos mais aventureiros, dominadores, agressivos, violentos e vitimizados. Constatou-se, também, que uma grande percentagem de personagens femininas usava roupas sexy e eram mais frequentemente, explícita e implicitamente, apresentadas como um objeto sexual (STEVEN, 1992; SOMMERS-FLANAGAN, R.; SOMMERSFLANAGAN, J.; DAVIS, 1993; WALLIS, 2011). As evidências demonstram que a exposição frequente a videoclipes está associada a maiores níveis de aceitação de atitudes sexuais estereotipadas e casuais, maiores expectativas acerca da atividade sexual ou dos resultados desta, maior aceitação de assédio sexual e, ocasionalmente, com maiores níveis de experiência sexual (STRASBURGER, 2004; WARD, 2003).

É por isso que faz sentido integrar os media e a sua análise nas intervenções e projetos de educação em sexualidade nas escolas, em particular no que diz respeito à violência no namoro. Permitirá não só compreender melhor as atitudes dos e das adolescentes, na forma como se relacionam, mas também atuar sobre elas, desconstruindo-as. Além disso, os e as docentes sentem necessidade de desenvolver 
estratégias mais apelativas e eficazes, enquadradas no dia-a-dia dos e das jovens, procurando ir ao encontro das suas vivências, ambientes, gostos e atitudes.

\section{Educação pelos pares e violência no namoro}

Arriaga e Foshee (2004) e Johnson et al. (2005) mostraram que é mais provável que adolescentes cometam violência nas suas relações, se os seus pares tiverem relações que envolvam violência. A informação que partilham entre si pode ser incorreta ou pouco precisa, em algumas circunstâncias legitimadora ou minimizadora da violência exercida ou, ainda, porque os e as jovens replicam nos relacionamentos de namoro as competências sociais que reforçaram com os pares. Contudo, os pares podem também assumir-se como um fator protetor e promotor do envolvimento em comportamentos saudáveis, uma vez que relacionamentos positivos entre pares fornecem estruturas relacionais fundamentais para as relações de maior intimidade (WOLFE et al., 2006). Pelas razões acima descritas, numa intervenção que pretenda alterar normas sociais acerca da violência de género, devem ser incluídas estratégias que envolvam os pares (JOHNSON et al., 2005; VÉZINA et al., 2011). Para isso, os/as educadores/as de pares têm de ser formados e treinados nas áreas em que vão intervir. Dessa forma poderão constituir uma fonte de informação credível, fator essencial para que o processo de educação ocorra e resulte (TURNER; SHEPHERD, 1999).

\section{Objetivos}

O projeto de intervenção teve como objetivos:

- diminuir a aceitação de atitudes de legitimação da violência física, psicológica e sexual nas relações de namoro através da exploração de um videoclipe;

- identificar estereótipos de género, mitos e comportamentos de risco presentes no videoclipe, alertando para a sua influência na construção de conceções acerca das relações de namoro;

- promover atitudes informadas em relação ao fenómeno da violência do namoro, nas suas dimensões física, psicológica e sexual;

- sensibilizar os e as adolescentes para a violência no namoro, através de sessões organizadas pelos seus pares; 
- sensibilizar pais, mães e encarregados/as de educação para a violência nas relações de namoro, nomeadamente, os sinais de alerta, o impacto na vítima, tipos de violência e formas de controlo;

\section{Método(s)}

O estudo foi desenvolvido de acordo com a metodologia de trabalho de projeto e procurou fazer uma intervenção de prevenção primária em adolescentes do ensino secundário acerca do tema violência no namoro. Considerou-se que: a) os media influenciam as atitudes dos jovens nos seus relacionamentos e b) a música está presente no dia-a-dia das vidas dos e das adolescentes e c) a visualização de videoclipes tem influência na legitimação de atitudes de violência no namoro. Assim, uma abordagem, em contexto de sala de aula, de desconstrução de concepções presentes (explícita ou implicitamente) num videoclipe, poderá contribuir para sensibilizar os e as adolescentes para a problemática, melhorando a sua percepção de atitudes de violência no namoro.

O projeto contemplava atividades diferentes e dirigidas a diversos públicos-alvo. No total envolveu 80 alunos e alunas do Ensino Secundário e 12 encarregados/as de educação. Na turma de $12^{\circ}$ ano, com quinze alunos/as, 7 rapazes (47\%) e 8 raparigas (53\%), foram realizadas 3 sessões de 90 minutos sobre "violência no namoro". Um grupo de alunos/as da turma teve, posteriormente, 2 outras sessões para preparar a sensibilização para as restantes turmas do secundário. O outro grupo de alunos/as teve mais 2 sessões onde preparou a sensibilização para pais, mães e encarregados/as de educação.

Foram recursos do projeto: i) a versão para investigação da Escala de Atitudes acerca da Violência no Namoro (EAVN) adaptada de Attitudes Toward Dating Violence Scale para a realidade portuguesa por Saavedra, Machado e Martins (2008 apud SAAVEDRA, 2010); ii) o videoclipe da música "Love the way you lie" de Rhianna e Eminem e a letra da música, acompanhados da ficha de exploração do videoclipe e de exploração da letra da música; iii) os depoimentos de vítimas de violência no namoro; iv) o anúncio da APAV sobre violência doméstica; e v) questionários de satisfação.

Antes de iniciar as sessões de formação todos os e as estudantes do ensino secundário da escola responderam ao questionário EAVN de forma a averiguar a aceitação de atitudes de violência psicológica, física e sexual nas relações de namoro. $\mathrm{O}$ questionário foi preenchido online usando um formulário do Google Docs. 
A escala utilizada é composta por setenta e seis itens, divididos por seis subescalas - (1) Atitudes acerca da violência psicológica masculina (VPM), com 15 itens, (2) Atitudes acerca da violência física masculina (VFM), com 12 itens, (3) Atitudes acerca da violência sexual masculina (VSM), com 12 itens, (4) Atitudes acerca da violência psicológica feminina (VPF), com 12 itens (5) Atitudes acerca da violência física feminina (VFF), com 13 itens e (6) Atitudes acerca da violência sexual feminina (VSF), com 12 itens. Alguns dos itens foram elaborados de modo a que a concordância fosse associada a maiores níveis de legitimação, enquanto em outros itens a concordância estava associada a menores níveis de legitimação dos comportamentos violentos. A maioria dos itens é cotada de 1 a 5 (1=discordo totalmente; $2=$ discordo; 3=não concordo nem discordo; 4=concordo; 5=concordo totalmente); os restantes, são codificados de forma invertida ( $1=$ concordo totalmente; $2=$ concordo; $3=$ não concordo nem discordo; 4=discordo; $5=$ discordo totalmente). $O$ valor de cada subescala será calculado pela soma dos seus itens. Pontuações mais elevadas apontam uma maior legitimação da utilização de comportamentos abusivos nos relacionamentos (Saavedra, 2010). Esta escala foi especificamente formulada e adaptada para ser utilizada junto da população juvenil e reconhece a importância de avaliar, dentro dos relacionamentos de namoro, outras formas de violência para além da violência física, valorizando comportamentos de agressão psicológica e sexual (SAAVEDRA, 2010).

$\mathrm{Na}$ tabela 1 resumem-se as atividades levadas a cabo nas três sessões de 90 minutos aos/às alunos/as do $12^{\circ}$ ano.

\section{Tabela 1 - Atividades dinamizadas nas sessões de sensibilização/formação à turma de $12^{\circ}$ ano}

\begin{tabular}{|c|c|}
\hline $\begin{array}{l}\text { Sessão 1 } \\
\text { (90 min) }\end{array}$ & $\begin{array}{l}\text { - Visionamento do videoclipe "Love the way you lie" de Rhianna e Eminem ( } 2 \text { grupos); } \\
\text { - trabalho de grupo: análise do videoclipe e respetiva letra através da utilização de } 2 \text { fichas } \\
\text { de exploração ( } 4 \text { grupos); } \\
\text { - discussão feita entre pares seguida de debate alargado à turma sobre o trabalho realizado. }\end{array}$ \\
\hline $\begin{array}{l}\text { Sessão } 2 \\
(90 \mathrm{~min})\end{array}$ & $\begin{array}{l}\text { - Apresentação de um powerpoint: } \\
\text { * descodificação dos sentimentos expressos no videoclipe; } \\
\text { * sexo e género, estereótipos de género e violência de género; } \\
\text { * conceito de violência no namoro; } \\
\text { * influência dos media nas relações de namoro e na banalização de atos violentos; } \\
\text { * comportamentos do/a agressor/a; } \\
\text { * razões para manter uma relação violenta e consequências para a vítima; } \\
\text { * como ajudar a vítima; } \\
\text { * características de relações saudáveis. } \\
\text { - Desconstrução de conceções e mitos relacionados com a violência no namoro. }\end{array}$ \\
\hline
\end{tabular}


Sessão 3 - Apresentação de depoimentos de vítimas de violência no namoro;

(90 min) - dramatização dos depoimentos com posterior discussão das situações representadas.

Fonte: Elaboração própria.

Foram utilizadas duas fichas de exploração, uma do videoclipe e outra da letra da música. Da ficha de exploração do videoclipe constam 4 questões de resposta curta/fechada e 5 questões de resposta aberta. A ficha de exploração da letra da música é constituída por 3 questões de resposta curta/fechada e 3 questões de resposta aberta. Estas fichas foram realizadas em grupos mistos. Dois grupos visualizaram o videoclipe e analisaram a ficha correspondente. Dois outros grupos analisaram a ficha de exploração da letra. As respostas dos/as alunos/as foram agrupadas em diferentes categorias visando percepcionar as concepções dos e das jovens em relação a situações de violência, nomeadamente: os sentimentos expressos, os estereótipos associados, os comportamentos característicos do/a agressor/a e da vítima, os mitos nas relações de namoro, o auxílio à vítima e incentivo à denúncia e as características das relações saudáveis.

Constituíram-se as seguintes categorias de análise, que se referem a uma relação de namoro, em particular a encenada no videoclipe:

Tabela 2 - Categorias de análise das fichas de exploração utilizadas

\begin{tabular}{|l|c|c|}
\hline \multirow{2}{*}{ Categorias de resposta } & \multicolumn{2}{|c|}{ Questões } \\
\cline { 2 - 3 } & $\begin{array}{c}\text { Ficha de exploração do } \\
\text { videoclipe }\end{array}$ & $\begin{array}{c}\text { Ficha de exploração } \\
\text { da letra da música }\end{array}$ \\
\hline Familiaridade com o videoclipe & 1 & 1,3 \\
\hline $\begin{array}{c}\text { Sentimentos expressos e características dos } \\
\text { personagens }\end{array}$ & $2,3,4$ & 4 \\
\hline Estereótipos de género & 5 & 5 \\
\hline Mitos nas relações de namoro & 6 & 2,6 \\
\hline Auxílio à vítima e incentivo à denúncia & $7,8,9$ & \\
\hline
\end{tabular}

Fonte: Elaboração própria.

O videoclipe escolhido constituiu um contributo para o debate sobre "violência doméstica" em particular a "violência no namoro", revelando-se bastante útil no que diz respeito à educação e orientação desse tema.

Os e as participantes das sessões bem como os/as dinamizadores/as preencheram um questionário de satisfação. 
Finalmente, numa última sessão, os/as alunos/as voltaram a preencher o questionário EAVN e um questionário de satisfação.

\section{Resultados principais}

\section{Resultados das fichas de análise e debate na turma}

Apresentam-se os principais resultados obtidos quer pelas respostas dadas pelos grupos às perguntas de cada uma das fichas, quer dos comentários que a formadora considerou relevantes da discussão no grupo e ainda na discussão alargada à turma.

Pôde observar-se que o videoclipe, era conhecido de todos os/as alunos/as. Alguns alunos/as conheciam aspetos da vida privada da cantora e, conheciam também a letra da música de cor.

Em relação aos sentimentos expressos e características dos personagens, delineou-se a percepção de que os comportamentos masculinos de violência foram mais facilmente desculpabilizados pelos grupos que os comportamentos femininos. Alguns dos alunos referiram que a rapariga era sensual e que se vestia de forma provocante, apontando para alguma desculpabilização das agressões do rapaz como se ele só a agredisse porque ela o provoca. Além disso, disseram que ele era paranóico e alucinado, associando os seus comportamentos a uma doença do foro psicológico o que, também pode indiciar uma desculpabilização das suas atitudes como se ele não tivesse controlo dos seus comportamentos uma vez que está doente (MAGALHÃES, 2010). Esta desculpabilização do homem também foi identificada quando associam a oferta de presentes à namorada como submissão do rapaz. Tal como Matos, M. et al. (2006) referem, o controlo masculino sobre a parceira bem como comportamentos de agressividade numa relação são ainda culturalmente legitimados e valorizados. Inicialmente os/as alunos/as não entendiam, como manipulação, os pedidos de desculpa do rapaz.

Os estereótipos de género surgem implicitamente nos diálogos: é o lado dela a pensar e o lado dele a agir, mesmo sem que os/as aluno/as se apercebam, demonstrando que, no fundo, as concepções estão presentes na forma como se relacionam e como agem perante situações problema. Num dos tópicos "ser agressivo/a com o teu/tua namorado/a se ele/a te traiu" as alunas, mais que os alunos, mostraram concordância com a agressão psicológica em caso de traição pelo/a namorado/a. Apesar de 
demonstrarem saber que não é a atitude mais aceite, reconhecem ser essa a que adotam no seu dia-a-dia.

A categoria mitos nas relações de namoro foi a que mais dúvidas suscitou, nomeadamente, a possibilidade dos ciúmes serem uma prova de amor bem como o envio constante de mensagens, tendo surgido no debate uma outra situação: a leitura de mensagens do telemóvel pelo/a parceiro/a. Ler as mensagens do/a parceiro/a não era percepcionado pelos alunos como uma atitude de controlo mas sim como um direito que o/a parceiro/a tinha por ser namorado/a. Os casais de namorados confundem frequentemente o ciúme e controlo, com amor, esperando que a violência no namoro conduza a um compromisso (WEKERLE; WOLFE, 1999).

$\mathrm{Na}$ categoria de análise auxílio à vítima e incentivo à denúncia, surgiu uma expressão curiosa: ela pode ser submissa sempre, pode não abrir os olhos. Sugerindo que a vítima não se apercebe que está numa relação violenta ou, por outro lado, que gosta da relação que tem. Sendo que, mais uma vez, se desculpabiliza o comportamento do homem agressor e critica a impotência da vítima para mudar a situação. A incompreensão das atitudes da vítima que opta pela manutenção de uma relação violenta é bastante clara nas respostas dadas demonstrando pouca compaixão pela vítima. De acordo com Lewis e Fremouw (2001) uma mulher vítima de violência poderá optar por ficar numa relação de violência por acreditar que a alternativa não é suficientemente atrativa para que termine a relação; outra hipótese é sentir que não está pronta para terminar uma relação na qual investiu tanto. Não significa que as vítimas queiram ser abusadas mas sim que, escolhem manter a relação apesar do abuso. Os grupos referiram a importância de levar a vítima a fazer uma denúncia.

\section{$\underline{\text { Resultados dos questionários EAVN }}$}

Nas tabelas seguintes apresentam-se os resultados do questionário para cada uma das dimensões avaliadas relativas às atitudes de violência física (VF), psicológica (VP) e sexual (VS) nas relações de namoro, por rapazes (M) e raparigas (F). Na tabela 3 estão expostos os resultados da média dos valores obtidos para a turma do $12^{\circ}$ ano antes e após a intervenção bem como a média dos valores obtidos para todos/as os/as alunos/as do ensino secundário.

Tabela 3 - Resultados do questionário EAVN para o total de alunos/as do ensino secundário e para os/as alunos/as do $12^{\circ}$ ano antes e após a intervenção 


\begin{tabular}{|c|c|c|c|c|c|c|c|}
\hline & & VPM & VFM & VSM & VPF & VFF & VSF \\
\hline & Média & $30,5 \pm 8,1$ & $21,0 \pm 7,5$ & $21,8 \pm 8,3$ & $24,9 \pm 7,4$ & $26,5 \pm 7,8$ & $26,0 \pm 9,1$ \\
\hline Total & $\mathrm{N}^{\circ}$ alunos/as & 80 & 80 & 79 & 79 & 79 & 79 \\
\hline $\begin{array}{c}12^{\circ} \text { ano } \\
\text { (antes da } \\
\text { intervenção) }\end{array}$ & $\begin{array}{l}\text { Média } \\
\mathrm{N}^{\mathrm{o}} \text { alunos/as }\end{array}$ & $\begin{array}{c}32,3 \pm 8,1 \\
15\end{array}$ & $\begin{array}{c}26,5 \pm 7,2 \\
15\end{array}$ & $\begin{array}{c}24,8 \pm 5,6 \\
15\end{array}$ & $\begin{array}{c}27,4 \pm 8,1 \\
15\end{array}$ & $\begin{array}{c}27,7 \pm 6,3 \\
15\end{array}$ & $\begin{array}{c}26,6 \pm 8,7 \\
15\end{array}$ \\
\hline $\begin{array}{c}12^{\circ} \text { ano } \\
\text { (após a } \\
\text { intervenção) }\end{array}$ & $\begin{array}{l}\text { Média } \\
\mathrm{N}^{\mathrm{o}} \text { alunos/as }\end{array}$ & $\begin{array}{c}26,7 \pm 10,5 \\
15\end{array}$ & $\begin{array}{c}22,1 \pm 8,6 \\
15\end{array}$ & $\begin{array}{c}20,7 \pm 8,8 \\
15\end{array}$ & $\begin{array}{c}22,0 \pm 10,0 \\
15\end{array}$ & $\begin{array}{c}23,3 \pm 7,9 \\
15\end{array}$ & $\begin{array}{c}22,7 \pm 9,8 \\
15\end{array}$ \\
\hline
\end{tabular}

Fonte: Elaboração própria.

Relativamente à análise dos resultados do questionário EAVN para a comparação dos/as estudante da turma do $12^{\circ}$ ano com os restantes estudante do ensino secundário pode constatar-se que estes apresentavam, inicialmente, valores médios de legitimação da violência no namoro, nas várias dimensões avaliadas, superior à média dos valores obtidos para o total dos/as alunos/as do ensino secundário. Após a intervenção, os valores obtidos são inferiores à média do total dos/as alunos/as do ensino secundário em todas as dimensões avaliadas com exceção da VFM que, apesar de ter descido em relação ao valor inicial, ainda se mantém ligeiramente acima da média do total dos/as estudantes.

Na tabela 4 estão representados os resultados da intervenção na turma do $12^{\circ}$ ano relativamente à aceitação de atitudes de violência no namoro.

Tabela 4 - Resultados do questionário EAVN para os alunos do $12^{\circ}$ ano

\begin{tabular}{|c|c|c|c|c|c|}
\hline & $\bar{x} \pm \sigma$ & $\begin{array}{c}\text { Diminuiçãa da } \\
\text { legitimação da } \\
\text { violência } \\
\end{array}$ & $\begin{array}{c}\text { Aumento da } \\
\text { legitimação da } \\
\text { violência } \\
\end{array}$ & $\begin{array}{c}\text { Manteve a } \\
\text { legitimação } \\
\text { da violência }\end{array}$ & $\operatorname{sig}(p)$ \\
\hline \multirow{2}{*}{$\begin{array}{l}\text { VPM após intervenção } \\
\text { VPM antes intervenção }\end{array}$} & $26,7 \pm 10,5$ & \multirow{2}{*}{$\begin{array}{c}80,0 \% \\
(12 \text { alunos })\end{array}$} & \multirow{2}{*}{$\begin{array}{c}7,7 \% \\
\text { (1 aluno) }\end{array}$} & \multirow{2}{*}{$\begin{array}{c}13,3 \% \\
\text { (2 alunos) }\end{array}$} & \multirow{2}{*}{$0,003 *$} \\
\hline & $32,3 \pm 8,1$ & & & & \\
\hline \multirow{2}{*}{$\begin{array}{l}\text { VFM após intervenção } \\
\text { VFM antes intervenção }\end{array}$} & $22,1 \pm 8,6$ & \multirow{2}{*}{$\begin{array}{c}86,7 \% \\
\text { (13 alunos) }\end{array}$} & \multirow{2}{*}{$\begin{array}{c}0,0 \% \\
(0 \text { alunos })\end{array}$} & \multirow{2}{*}{$\begin{array}{c}13,3 \% \\
(2 \text { alunos })\end{array}$} & \multirow{2}{*}{$0,001^{*}$} \\
\hline & $26,5 \pm 7,2$ & & & & \\
\hline \multirow{2}{*}{$\begin{array}{l}\text { VSM após intervenção } \\
\text { VSM antes intervenção }\end{array}$} & $20,7 \pm 8,8$ & \multirow{2}{*}{$\begin{array}{c}66,7 \% \\
\text { (10 alunos) }\end{array}$} & \multirow{2}{*}{$\begin{array}{c}13,3 \% \\
\text { (2 alunos) }\end{array}$} & \multirow{2}{*}{$\begin{array}{c}20,0 \% \\
\text { (3 alunos) }\end{array}$} & \multirow{2}{*}{$0,018^{*}$} \\
\hline & $24,8 \pm 5,6$ & & & & \\
\hline \multirow{2}{*}{$\begin{array}{l}\text { VPF após intervenção } \\
\text { VPF antes intervenção }\end{array}$} & $22,0 \pm 10,0$ & \multirow{2}{*}{$\begin{array}{c}80,0 \% \\
\text { (12 alunos) }\end{array}$} & \multirow{2}{*}{$\begin{array}{c}0,0 \% \\
\text { (0 alunos) }\end{array}$} & \multirow{2}{*}{$\begin{array}{c}20,0 \% \\
\text { (3 alunos) }\end{array}$} & \multirow{2}{*}{$0,002^{*}$} \\
\hline & $27,4 \pm 8,1$ & & & & \\
\hline \multirow{2}{*}{$\begin{array}{l}\text { VFF após intervenção } \\
\text { VFF antes intervenção }\end{array}$} & $23,3 \pm 7,9$ & \multirow{2}{*}{$\begin{array}{c}80,0 \% \\
\text { (12 alunos) }\end{array}$} & \multirow{2}{*}{$\begin{array}{c}0,0 \% \\
(0 \text { alunos) }\end{array}$} & \multirow{2}{*}{$\begin{array}{c}20,0 \% \\
\text { (3 alunos) }\end{array}$} & \multirow{2}{*}{$0,000 * *$} \\
\hline & $27,7 \pm 6,3$ & & & & \\
\hline \multirow{2}{*}{$\begin{array}{l}\text { VSF após intervenção } \\
\text { VSF antes intervenção }\end{array}$} & $22,7 \pm 9,8$ & \multirow{2}{*}{$\begin{array}{c}73,3 \% \\
\text { (11 alunos) }\end{array}$} & \multirow{2}{*}{$\begin{array}{c}0,0 \% \\
\text { (0 alunos) }\end{array}$} & \multirow{2}{*}{$\begin{array}{c}27 \% \\
\text { (4 alunos) }\end{array}$} & \multirow{2}{*}{$0,002 * *$} \\
\hline & $26,6 \pm 8,7$ & & & & \\
\hline
\end{tabular}


* Teste de Wilcoxon ** Teste t-emparelhado

Valores significativos para $p<0,05$

Fonte: Elaboração própria.

Resultados da aplicação do teste de Wilcoxon e t-emparelhado aos questionários demonstraram que as diferenças entre os resultados iniciais e finais são estatisticamente significativas em todas as dimensões avaliadas. A diminuição da legitimação da violência situa-se entre os 66,7\% para a Violência Sexual Masculina (VSM) e os 86,7\% na Violência Física Masculina (VFM).

\section{Resultados dos questionários de satisfação}

A maioria dos/as alunos/as do $12^{\circ}$ ano referiu ter aprendido algo que não sabia e gostaram das dinâmicas propostas. Em relação aos/às alunos/as que frequentaram as sessões de sensibilização pelos pares saliento que todos/as consideraram o assunto da ação pertinente, a maioria reconheceu que aprendeu coisas que não sabia e gostou de terem sido os/as colegas a dinamizar a sessão. Os pais, mães e encarregados/as de educação gostaram do facto da sessão ter sido preparada pelos/as alunos/as e referiram que os/as deixa felizes, saberem que os seus filhos/as tenham conhecimentos sobre este tema. Ainda de realçar que dada a dificuldade de adesão das famílias às iniciativas promovidas pela escola, serem os/as alunos/as a dinamizar as atividades aumentou o número de pais e mães presentes na sessão.

\section{Conclusões}

Baseada na proposta de Saavedra (2010) usou-se a sua investigação como ponto de partida para novos esforços de prevenção da violência nos relacionamentos íntimos. Este projeto foi levado a cabo com o intuito de diminuir a incidência de atitudes de legitimação da violência nos relacionamentos íntimos em jovens do ensino secundário.

Considera-se que os objetivos do projeto foram cumpridos de forma muito satisfatória uma vez que a) se verificou a diminuição da legitimação da violência física, psicológica e sexual nas relações de namoro; b) se identificaram estereótipos e comportamentos de risco presentes em videoclipes, alertando para a sua influência na construção de concepções acerca das relações de namoro; c) foram identificados mitos, atitudes ou crenças associados às relações de namoro; d) se promoveram atitudes mais 
informadas em relação ao fenómeno da violência do namoro, nas suas dimensões física, psicológica e sexual; e) se sensibilizaram os e as adolescentes para a violência no namoro, através de sessões organizadas pelos seus pares; f) se sensibilizaram pais, mães e encarregados/as de educação para a violência nas relações de namoro, nomeadamente os sinais de alerta, o impacto na vítima, tipos de violência e formas de controlo; $g$ ) foi incentivado o apoio à vítima e a denúncia de situações de abuso.

Tendo em conta os resultados obtidos pôde verificar-se que:

- Os e as adolescentes acreditam que o ciúme e o controlo podem ser uma prova de amor, sendo o telemóvel o instrumento privilegiado para exercer controlo sobre o/a parceiro/a;

- Existem estereótipos de género em videoclipes e que, a sua visualização pode favorecer a aceitação e desculpabilização de comportamentos estereotipados; fazer a desconstrução do videoclipe contribuiu para promover atitudes mais informadas em relação ao fenómeno da violência do namoro, nas suas dimensões física, psicológica e sexual, nomeadamente no que respeita aos comportamentos típicos do agressor, às consequências para a vítima bem como das razões pela qual a vítima mantém uma relação de violência;

- Houve uma diminuição da legitimação da violência física, psicológica e sexual nas relações de namoro.

No entanto, é importante mencionar que este projeto apresentou algumas limitações. Apesar de Antle et al. (2011) terem analisado vários estudos e concluído que, intervenções de curta duração que sejam bem focadas, possam ter impactes positivos nos conhecimentos dos e das adolescentes, no desenvolvimento de capacidades e em atitudes relacionadas com a violência no namoro e relações saudáveis, o tempo cingido a um ano letivo e o facto da implementação ter sido levada a cabo na aula, condicionou as tarefas propostas no projeto, nomeadamente, o número de sessões, os instrumentos utilizados e o número de alunos/as a quem se direcionou a formação. Por haver constrangimentos de tempo optou-se pela realização, em grupo, das fichas de exploração permitindo o debate dentro do grupo enriquecendo os diálogos, apesar de reduzir o número de dados a analisar. Os resultados do questionário EAVN sobre a legitimação da violência nas relações de namoro podem estar aquém do que realmente acontece pois os e as adolescentes tendem a dar respostas socialmente aceites, em particular em assuntos sensíveis como o da violência no namoro, mesmo sendo os questionários anónimos (CORNELIUS; RESSEGUIE, 2007; SAAVEDRA, 2010). 


\section{Implicações}

Considera-se que as atividades dinamizadas e estratégias implementadas tiveram sucesso junto dos/as alunos/as pelo interesse demonstrado nas sessões de formação e empenho na preparação das atividades para os/as colegas, pais, mães e encarregados/as de educação. Assim, recomenda-se implementar projetos de educação em sexualidade e media na escola, com recurso à educação pelos pares.

Para finalizar, realça-se, ainda, a necessidade de formação de professores/as, no sentido de melhor se poder responder às exigências da educação em sexualidade em contexto escolar.

\section{A CLOSER LOOK ON DATING VIOLENCE: A PROJECT WITH SECONDARY EDUCATION TEENAGERS}

ABSTRACT: Over the past years violence in dating relationships has increased considerably endorsing the implementation of violence prevention projects in school environment. The main objective of this intervention was to diminish the legitimacy of violent attitudes in dating relationships. The use and thorough study of a specific music video revealed itself an innovative strategy in preventing dating violence, allowing adolescents to develop a critical look at the information conveyed by it. The implementation of this intervention project was undertaken at a school of the Leiria district and entirely aimed towards the secondary education student population including both parents and legal guardians. A total three sessions were conducted in a class of fifteen 12th grade students which later on impelled an awareness session at all other secondary school classes and another session addressed to parents and legal guardians. In order to evaluate the impact of the sessions, it was necessary to use and subsequently analyze study-sheets based on the music video and its lyrics, as well as the Portuguese version of the Attitude Scale Facing Violence in Dating (EANV). A statistically significant decrease in the legitimation of violence was registered among the intervened students. Most of the participants referred the importance of this type of sessions and enjoyed the activities and strategies applied. The activities undertaken and, in particular, the use of music videos and sessions prepared by students, are a strong contribute in actions targeting the prevention of dating violence.

KEYWORDS: Dating violence. Music vídeos. Sexuality and media. School intervention. 


\section{REFERÊNCIAS}

ACKARD, D. M.; EISENBERG, M. E.; NEUMARK-SZTAINER, D. Long-term impact of adolescent dating violence on the behavioral and psychological health of male and female youth. Journal of Pediatrics, [S.1.], v.151, n.5, p.476-481, 2007.

AMAR, A. F.; GENNARO, S. Dating violence in college women: associated physical injury, healthcare usage, and mental health symptoms. Nursing Research, [S.1.], v.54, n.4, p.235-242, 2005.

ANTLE, B. F. et al. Healthy relationship education for dating violence prevention among high-risk youth. Children and Youth Services Review, [S.1.], v.33, n.1, p.173179, 2011.

ARRIAGA, X. B. ; FOSHEE, V. A. Adolescent dating violence. Do adolescents follow in their friends 'or their parents' footsteps? Journal of Interpersonal Violence, [S.l.], v.19, n.2, p.162-184, 2004.

BETHKE, T. M.; DEJOY, D. M. An experimental study of factors influencing the acceptability of dating violence. Journal of Interpersonal Violence, [S.1.], v.8, n.1, p.36-51, 1993.

CARIDADE, S.; MACHADO, C. Violência na intimidade juvenil: da vitimação à perpetração. Análise Psicológica, Lisboa, v.24, n.4, p.485-493, out. 2006.

CORNELIUS, T. L.; RESSEGUIE, N. Primary and secondary prevention programs for dating violence: a review of the literature. Aggression and Violent Behavior, [S.1.], v.12, p.364-375, 2007.

COUNCIL ON COMMUNICATIONS AND MEDIA. Impact of music, music lyrics, and music videos on children and youth. Pediatrics, [S.1.], v.124, n.5, p.1488-1494, nov. 2009.

DRAUCKER, C. B.; MARTSOLF, D. S. The role of electronic communication technology in adolescent dating violence. Journal of Child and Adolescent Psychiatric Nursing, [S.1.], v.23, n.3, p.133-142, 2010.

FOSHEE, V. A. et al. The safe dates project: theoretical basis, evaluation design, and selected baseline findings. American Journal of Preventive Medicine, [S.1.], v.12, n.2, p.39-47, 1996.

GRAY, H. M.; FOSHEE, V. Adolescent dating violence: differences between one-sided and mutually violent profiles. Journal of Interpersonal Violence, [S.1.], v.12, n.1, p.126-141, feb. 1997.

HAYS, D. et al. A phenomenological investigation of adolescent dating relationships and dating violence counseling interventions. The Professional Counselor, Greensboro, v.1, n.3, p.222-233, 2010.

HENTON, J. et al. Romance and violence in dating relationships. Journal of Family Issues, Flórida, v.4, p.467-482, 1983. 
JACKSON, S. M.; CRAM, F.; SEYMOUR, F. W. Violence and sexual coercion in high school student's dating relationships. Journal of Family Violence, [S.1.], v.15, n.1, p.23-36, 2000.

JOHNSON, S. et al. "I know what love means". Gender-based violence in the lives of urban adolescents. Journal of Women's Health, Washington, v.14, n.2, p.172-179, 2005.

KRUG, E. G. et al. (Ed.). World report on violence and health. Geneva: World Health Organization, 2002.

LEWIS, S. F.; FREMOUW, W. Dating violence: a critical review of the literature. Clinical Psychology Review, [S.1.], v.21, n.1, p.105-127, 2001.

MAGALHÃES, T. Violência e abuso: respostas simples para questões complexas. Coimbra: Imprensa da Universidade de Coimbra, 2010.

MANGANELLO, J. A. Teens, dating violence, and media use: a review of the literature and conceptual model for future research. Trauma, Violence, \& Abuse, [S.1.], v.9, n.1, p.3-18, 2008.

MATOS, M. Violência nas relações de intimidade: estudos sobre a mudança psicoterapêutica da mulher. 386f. 2006. Tese (Doutorado em Psicologia) - Universidade do Minho, Braga, 2006.

. et al. Prevenção da violência nas relações de namoro: intervenção com jovens em contexto escolar. Psicologia: Teoria e Prática, São Paulo, v.8, n.1, p.55-75, 2006.

MATOS, M. G. et al. A saúde dos adolescentes portugueses. Relatório do estudo HBSC 2010. 1.ed. Lisboa: Aventura Social \& Saúde, 2010. Disponível em: <http://aventurasocial.com/publicacoes.php>. Acesso em: 27 jun. 2015.

O'KEEFE, M. Teen dating violence: a review of risk factors and prevention efforts. Harrisburg: VAWnet, 2005. Disponível em:

<http://www.vawnet.org/Assoc_Files_VAWnet/AR_TeenDatingViolence.pdf >. Acesso em: 27 jun. 2015.

O'LEARY, K. D. et al. Gender differences in dating aggression among multiethnic high school students. Journal of Adolescent Health, New York, v.42, n.5, p.473-479, 2008.

ORTEGA, R.; RIVERA, F. J. O.; SÁNCHEZ, V. Violencia sexual entre compañeros y violencia en parejas adolescents. International Journal of Psychology and Psychological Therapy, [S.1.], v.8, n.1, p.63-72, 2008.

PORTUGAL. Lei n. ${ }^{\circ}$ 60/2009 de 6 de Agosto. Estabelece o regime de aplicação da educação sexual em meio escolar. Diário da República, 1a série, n.151, 6 ago. 2009. abr. 2010 .

. Portaria n. ${ }^{\circ}$ 196-A/2010 de 9 de Abril. Diário da República, $1^{\text {a }}$ série, n.69, 9 
IV Plano Nacional contra a Violência Doméstica (2011-2013). Presidência do conselho de ministros. Resolução do Conselho de Ministros n. ${ }^{\circ}$ 100/2010. Diário da República, $1^{\mathrm{a}}$ série, n.243, 17 dez. 2010.

RICH, M. Aggressors or victims: gender and race in music video violence. Pediatrics, [S.1.], v.101, n.4, p.669-674, 1998.

SAAVEDRA, R. M. M. Prevenir antes de remediar: prevenção da violência nos relacionamentos íntimos juvenis. 2010. Tese (Doutoramento em Psicologia - Psicologia da Justiça) - Universidade do Minho, Braga, 2010.

SAN MIGUEL, L. T.; FERNÁNDEZ, E. A. Lo que VD. debe saber sobre: violência de género. Léon: Rubín, 2010.

SILVERMAN, J. G. et al. Dating violence against adolescent girls and associated substance use, unhealthy weight control, sexual risk behavior, pregnancy and suicidality. Journal of the American Medical Association, [S.1.], v.286, n.5, p.572579, 2001.

SOMMERS-FLANAGAN, R.; SOMMERS-FLANAGAN, J.; DAVIS, B. What's happening on music television? A gender role content analysis. Sex roles, [S.1.], v.28, n.11-12, p.745-753, 1993.

STEVEN, A. Profile: an investigation of sex-role stereotyping in music videos. Journal of Broadcasting \& Electronic Media [online], v.36, n.2, p.209-216, 1992.

STRASBURGER, V. C. Children, adolescents, and the media. Current Problems in Pediatric and Adolescent Health Care, [S.1.], v.34, n.2, p.51-113, 2004. .; DONNERSTEIN, E. Children, adolescents, and the media: issues and solutions. Pediatrics, [S.1.], v.103, n.1, p.129-139, 1999.

SUDERMANN, M.; JAFFE, P. G.; HASTINGS, E. Violence prevention programs in secondary (high) schools. In: PELED, E.; JAFFE, P.; EDELSON, J. (Ed.). Ending the cycle of violence. Thousand Oaks: Sage, 1995. p.232-254.

TURNER, G.; SHEPERD, J. A method in search of a theory: peer education and health promotion. Health Education Research, Oxford, v.14, n.2, p.235-247, 1999.

UNESCO. Orientação técnica internacional sobre educação em sexualidade: uma abordagem baseada em evidências para escolas, professores e educadores em saúde. Tradução de R. Brossard. Brasília: UNESCO, 2010. v.1.

VEZINA, J. et al. Risky lifestyle as a mediator of the relationship between deviant peer affiliation and dating violence victimization among adolescent girls. Journal of Youth and Adolescence, [S.1.], v.40, p.814-824, 2011.

WALLIS, C. Performing gender: a content analysis of gender display in music videos. Sex Roles, [S.1.], v.64, p.160-172, 2011 
WARD, L. M. Understanding the role of entertainment media in the sexual socialization of American youth: a review of empirical research. Developmental Review, [S.1.], v.23, n.3, p.347-388, 2003.

WEKERLE, C.; WOLFE, D. Dating violence in mid-adolescence: theory, significance, and emerging prevention initiatives. Clinical Psychology Review, [S.1.], v.19, n.4, p.435-456, 1999.

WHO. World Health Organization. Intimate partner violence and alcohol. Geneva: World Health Organization, 2006.

WOLFE, D. A. Preventing violence in relationships: psychological science addressing complex social issues. Canadian Psychology, [S.1.], v.47, p.44-50, 2006. 